\title{
Tiempo y mirada en la obra de Hiroshi Sugimoto y Wolfgang Tillmans
}

\author{
Susana Santoyo
}

Este texto expone algunas relaciones entre tiempo y técnica en la fotografía, en términos de Walter Benjamin y José Luis Brea, pero también de la misma práctica. A partir de dichas relaciones, el texto propone concepciones de tiempo y mirada en el acto fotográfico que confrontan el mito que lo coloca en el papel de técnica instantánea que guarda el pasado. Hiroshi Sugimoto y Wolfgang Tillmans son ejemplos de estas concepciones propuestas, pues reflexionan en la práctica sobre tiempo y técnica.

PALABRAS ClAVE: Fotografía, Benjamin, técnica, Sugimoto, Tillmans.

This paper discusses some relations between time and technique in photography, in terms of Walter Benjamin and José Luis Brea, but also of the practice itself. From these relations, the paper proposes concepts of time and sight in the photographic act that confront the myth that places it in the role of an instant technique that preserves the past. Hiroshi Sugimoto and Wolfgang Tillmans are examples of these proposed conceptions, as both reflect in the practice on time and technique.

KEYWORDS: Photography, Benjamin, technique, Sugimoto, Tillmans.

Fecha de recepción: 8 de agosto de 2013

Fecha de aceptación: 24 de septiembre de 2013 

Susana Santoyo

\section{Tiempo y mirada en la obra de Hiroshi Sugimoto y Wolfgang Tillmans}
Y descubro inesperadamente que quedaban mundos enteros por explorar [...], en la mirada con que los miramos - tendría que decir: en la manera de mirar y en la manera de no mirar. ¿He sido un tímido todos estos años?

Tomás Segovia, Personajes mirando una nube

Se podría pensar que la seducción de la fotografía radica en la relación de dos tiempos: el pasado y el instante. Uno que se eterniza y el otro que no se deja escapar. Dos tiempos montados en un soporte, resultado de un proceso técnico que a lo largo de su historia ha sido descrito una y otra vez por historiadores, críticos y fotógrafos. El origen técnico, casi mágico, de la fotografía nos marea; aun cuando lo vemos con distancia, nos sigue dando comezón en la mirada.

Mención aparte merece la educación teórica que se comparte entre "humanistas", la cual dirige nuestras conclusiones a ciertos lugares no resueltos, a veces redundantes: que si la imagen es testigo o no de la realidad, que si es indexical o no, que si ahora la fotografía digital cambia nuestra perspectiva sobre el arte, sobre la misma imagen o no. Las preguntas se siguen acumulando y los pensadores les siguen dando vueltas, mientras los fotógrafos siguen produciendo imágenes, aunque 
estas también parecen repetirse. ¿Qué nos hace mirar una y otra vez lo mismo? ¿En dónde la pertinencia de repetirnos?

La fotografía sería, pues, la repetición de una acto que eterniza un pasado y retiene el instante. En principio, así parece. Sin embargo, algunos artistas parecen estar interesados en otras posibilidades del acto fotográfico. Valdría la pena mirarlos.

\section{Antecedentes: tiempo y técnica}

El arte en la época de su reproductibilidad técnica es un texto básico en la educación artística, y es menester preguntarse por su validez para el análisis de los procesos artísticos contemporáneos, pues la técnica y las capacidades de reproductibilidad del objeto artístico, tal como Benjamin las planteó, han sido superadas por los llamados nuevos medios. Acaso el sentido de la fotografía contemporánea apunte ya hacia otro lado, tal vez hacia la tradición que la misma técnica ha forjado, o tal vez olvide la técnica para ser parte de otros procesos de producción entre medios y entre medias.

Cuando Benjamin escribió este texto, en el periodo de entreguerras en Europa, la fotografía tenía apenas décadas de nacida y el cine era mucho más reciente. En la década de los veinte el lenguaje del montaje cinematográfico apenas cruzaba por el terreno de la experimentación y las definiciones. Benjamin publicó aquel texto en 1936, casi al mismo tiempo en que Jan Mukarovsky describiera el objeto artístico como un signo autónomo ("El arte como hecho semiológico"). Benjamin planteó que la técnica alejaba al objeto artístico de dicho carácter autónomo de la obra; pero no imaginaba hasta dónde la técnica, la que avalaba y alababa a lo largo del texto, podría inclinar su balanza hacia las "peligrosas tensiones de la tecnificación" (Benjamin, La obra de arte, 87). Una cosa era mencionar dicho peligro, pero otra muy diferente era imaginar lo inimaginable en esos tiempos, el monstruo Polaroid, y su bisnieto, el monstruo Instagram.

La fotografía particularmente es, en el texto de Benjamin, un parte aguas para el desarrollo de otro tipo de percepción de la realidad, de una mirada diferente, de una transmisión y exhibición más diversa de 
lo puesto en imagen, y sin duda más manipulable en términos de objeto artístico. Benjamin señala también el paso a la época del montaje en el arte, aunque él se refiere al cine, al acto de edición, a cortar y pegar, así como el inicio de los actos de ensamblaje, que han sido popularizados en los procesos contemporáneos. Si bien Benjamin no profundiza en ello, el señalamiento que hace es base para la comprensión de los actos y procesos artísticos actuales. El montaje no solo está en el corte y pegado de un fotograma, cortar y pegar tendrá consecuencias en el arte de proceso y en el arte conceptual, le dará forma y será manual de lectura. El montaje es el instructivo de la contemporaneidad. Este carácter de la posmodernidad, las herramientas prestadas de la cita, el corte y el pegado, que en la literatura se usaban antaño y que el arte aprehendería, sigue hoy en día marcando las maneras de hacer. Fragmentarios son los tiempos y las cabezas de nuestros actores culturales. Fragmentaria la imagen. La fotografía contemporánea explotaría el montaje en ese sentido, y también en el sentido de recrear: ahí está Jeff Wall con sus detallados montajes.

Entonces, ¿cómo traemos a lo contemporáneo lo dicho por Benjamin? Dice José Luis Brea, refiriéndose al aura benjaminiana en la contemporaneidad: "ese halo imaginario [...] ha cedido su lugar a otro más liviano y efímero, a un aura fría [ ]. Solo en tanto se cumple la ceremonia de la comunicación de su valencia, de su potencial de valor, a través del rito de la producción al infinito" (Las auras frías, 5), lo cual hace pensar que la producción artística bordea lo irreversible, como el mundo mismo pareciera volver a validar un "aquí y ahora" (Benjamin, La obra de arte, 42) omnipresente, que inserta de nuevo el rito en el sistema del arte. ¿Acaso José Luis Brea lo plantea como una vuelta poco optimista? Lo dudaría, por su intenso trabajo en y sobre los medios digitales. Lo que es claro es que intenta actualizar la relación técnica-imagen contemporánea.

Y aquí vuelvo a una de las preguntas del principio, este repetirse infinito, ¿de dónde viene y hacia dónde nos lleva? Nos quedamos absortos dando clics en Internet, de un hipertexto a otro, de enlace en enlace, abriendo ventanas y ventanas que no terminamos de ver, paseando por los museos virtuales, visitando el mundo, conociendo las obras de arte más famosas en un monitor con resolución 1680 x 1050. Las vemos 
diez segundos y las olvidamos. Y luego de todo eso, de la historia y los comentarios teóricos, luego de que Brea señalara las auras frías generadas por la hiper-repetición de la imagen, luego de eso, ¿qué pasa con nuestra recepción? Un arma de dos filos. El arte está a un clic de la gente, cualquiera con acceso a un dispositivo con pantalla y conectado a la red puede acceder remotamente a algo que es más que una ilustración, es la digitalización del objeto. Es el objeto. A través de una pantalla, pero ahí está, una delgada película de plasma separa a la población del conocimiento, de los detonadores de experiencias estéticas. Pero por otro lado, la misma película de plasma, como señala Brea, hace liviano y frío el contacto, diez segundos con la Victoria de Samotracia deberían bastar, veinte si es 3D.

\section{Dos casos: Sugimoto y Tillmans}

El mismo José Luis Brea diría "nada que ver, nada que ver" ("Lo has visto ya todo"), lo hemos visto todo, hemos repetido las imágenes que la humanidad ha catalogado como bellas o valiosas, hemos tomado el retrato de nuestros familiares para luego perder los álbumes y dejarlos en el anonimato, hemos fotografiado hasta cimbrarle los cimientos a todos los monumentos del mundo, y cada paisaje ha sido inmortalizado en cada segundo del día por otro nuevo turista. Hemos dado el estatus de arte al fotoperiodismo y, al tiempo, hemos borrado el valor de los hechos para ver la luz que refleja bellamente la frente del niño que está muriendo de hambre, cómo sus ojos enternecen al jurado, mientras se pide la impresión de dos por dos metros, para que reciba el premio. ¿Sí es esta la tecnificación de la que Benjamin advertía? ¿O simplemente estamos observando lo que pasa masivamente y no ponemos atención a otras propuestas fotográficas?

La técnica no solo ha sido observada para explotar sin fin la reproductibilidad de la imagen y poder compartirla en todos los formatos y resoluciones. Existe, por ejemplo, una "legión" (Hermoso, "El tiempo cabe en una caja") de personas utilizando cámaras estenopeicas (objetos sin lente, con un pequeño orificio o estenopo, que recuerda a las primeras cajas negras, que se pueden usar con papel fotográfico o con 
negativo, con los que no puede medirse con exactitud ni la luz ni las distancias) para generar imágenes. Manuales sobre cámaras estenopeicas caseras, productores especializados, galerías de este tipo de imágenes comienzan a convivir con las fotos llenas de filtros y compartidas cada segundo por usuarios de Instagram. Y no solo son aficionados. En México, fotógrafos con una carrera sólida, como Carlos Jurado, han dedicado su producción a las cajas sin lente. Y no solo ellos están preocupados por este otro tiempo fotográfico que la técnica facilita, pues, en una cámara así, el tiempo de la toma de imagen no es un clic instantáneo, se debe esperar y no se puede borrar como en un aparato digital, la toma es irreversible por definitiva (la irreversibilidad del principio de la fotografía).

Artistas como Hiroshi Sugimoto también están preocupados por otros tiempos en la fotografía y revisitan la técnica sin ir hasta la caja negra, aunque sin olvidar sus orígenes y principios. En su proyecto Theaters, realizado entre 1978 y principios de la década de los noventa, Sugimoto visitó algunos cines y vio, junto a su cámara, la película. La imagen contiene los cientos de minutos e imágenes que pasaron por la panta1la, aunque solo veamos luz, porque eso es lo que hay. Sugimoto nos muestra una materialidad de la luz, que es partícula y que modifica el negativo. Además, encapsula un tiempo presente, porque el acto fotográfico está pasando mientras él vive el momento. ¿Por qué un momento es reducido a una noción de instante, de fragmentos de segundo? En este proyecto, el diafragma, para hacer clic, ha estado abierto cientos de segundos, hasta cientos de minutos. Algo muy parecido a los primeros años de la fotografía, cuando la técnica demandaba minutos de vida a los modelos, que debían usar unos aparatos para soportar su cabeza y no "barrer" la imagen. No se ha escrito un libro sobre lo que hacían los fotógrafos mientras la luz dejaba huella en la película, al menos sabemos que Sugimoto vio varios filmes en cines hermosos.

En la foto existe un momento, el referente no es solo aquello que está fragmentado y representado en la imagen, el corte de realidad lleva consigo parte del contexto. Además, el fotógrafo ha tenido una postura al tomar la fotografía, o ha usado un tripié. El fotógrafo mira para componer, decidir y hacer la toma. 


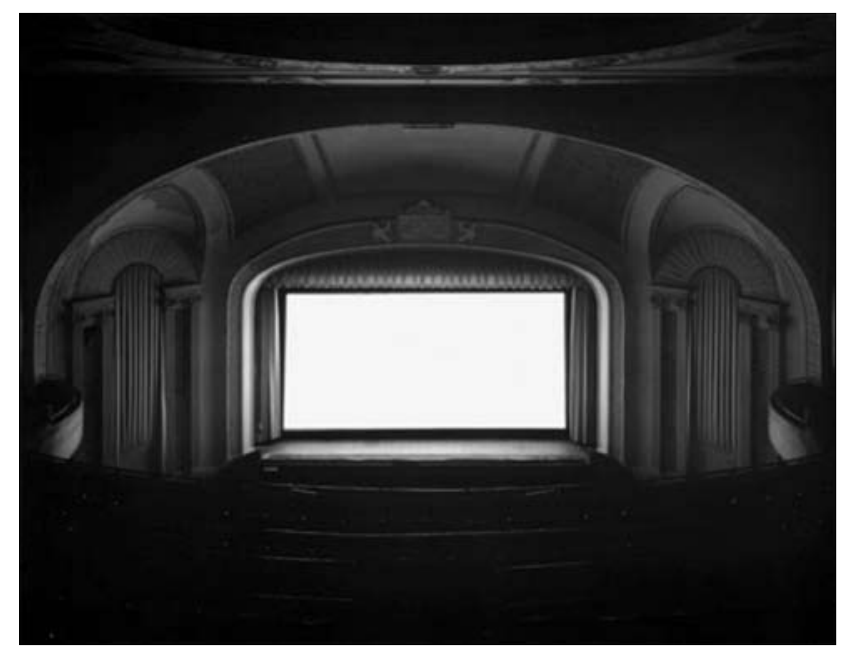

HIROSHI Sugimoto. U.A. Play house. Plata s/gelatina. Medidas variables, 1978

Por su parte, Wolfgang Tillmans nos invita a ver el mundo como un lugar para el asombro, a mirar aquellos detalles que pasamos por alto porque ya hemos visto todo y lo hemos fotografiado miles de veces. En la mirada que ha dedicado una vida a fotografiar, existe una capacidad de asombro que va en contra de la marea de la repetición contemporánea, aunque paradójicamente nos muestre los objetos que tenemos a nuestro alrededor. Un aspecto interesante de este fotógrafo es su conciencia de la materialidad de la fotografía, del material impreso: además de generar libros, expone las fotografías sin marco. Él es un fotógrafo de la foto y del color, fotografía lo puramente técnico para mostrarlo como objeto. Para Tillmans, eso que vemos en una fotografía, que pareciera el atardecer, "no es el cielo, es el pigmento azul adherido al papel" (Tillmans, Entrevista). Este es otro carácter de la técnica que Benjamin no pensó y que sin duda Brea no considera como objeto con una aura fría. Y no es que los objetos e imágenes de Tillmans sean irrepetibles, sin duda ese no es su interés, pero su metafotografía descubre la técnica, sin ser un tradicional paisaje de Jurado, ni un documental sobre la técnica fotográfica; no son ociosos experimentos de laboratorio, Tillmans reflexiona sobre la imagen en la imagen, presenta la imagen, en tanto presenta el objeto. Si fotografiar es un acto, el testimonio 
del acto no es aquí la huella del referente, es lo que vemos, el pigmento en un papel, que ha sido procesado, pero que está relacionado con una serie de imágenes fotográficas en sentido estricto.

La obra de Tillmans no es una imagen, o una serie. La obra es la exposición, el montaje completo en sala, o en todo caso, el libro. Es el conjunto de ensayos experimentales con sus fotos del cotidiano, naturalezas muertas, retratos, las mesas de trabajo, fotografías dentro de fotografías impresas en sus libros.

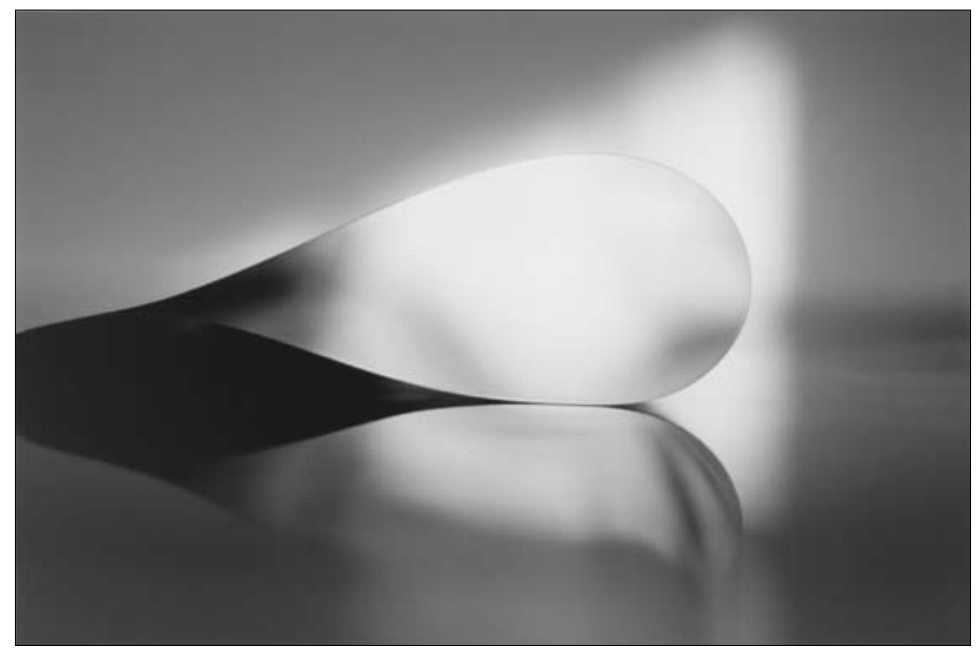

WOLFGANG Tillmans. Paper drop (window). Imagen cromógena, medidas variables, 2006

Estos fotógrafos poseen la capacidad técnica para obtener imágenes que cualquiera catalogaría de "bien hechas", de acuerdo a las convenciones de lo que es una imagen fotográfica, pero esa capacidad es usada para reflexionar el medio, para asombrarse del mundo porque se dan tiempo de mirar y de mirar su propia herramienta, que no es su cámara ni su laboratorio, es lo que aquellos fotógrafos de principios del siglo $\mathrm{xx}$ desarrollaron mejor: la mirada.

Ahora mismo, estos artistas confrontan la "necesidad" de eternizar el instante y conservar el pasado. El tiempo del acto fotográfico mismo vuelve a cobrar importancia, el tiempo de preguntarse: ¿qué pasaba en 
ese momento? No solo con la imagen, con el contexto, con el fotógrafo. Porque la técnica no es solo el laboratorio, ni la óptica, ni la digitalización, ni la capacidad de obtener miles de copias; es una serie de cualidades aprendidas, como oficio, que indudablemente tienen que ver con la luz y el tiempo, y con mirar. Todas ellas pueden usarse para detonar reflexiones en torno al tiempo mismo de la fotografía. El tiempo de la fotografía es más extenso que el instante y su función está más allá de ser huella. El acto fotográfico está en la mirada, no en el dedo del fotógrafo, en el clic no se mide el tiempo. El tiempo de la fotografía es tan largo como el montaje de una foto de Jeff Wall, los meses que tarda Tillmans en armar una naturaleza muerta o una película que ha mirado Sugimoto.

\section{REFERENCIAS}

Benjamin, Walter, La obra de arte en la época de su reproductibilidad técnica, México, Itaca, 2003.

BREA, José Luis, Las auras frías. El culto a la obra de arte en la era postaurática, $<$ http://joseluisbrea.net/ediciones_cc/auras.pdf $>$ [20/05/2013].

BREA, José Luis, "Lo has visto ya todo, no hay nada más que ver", en Arts Zin, $<$ http://www.artszin.net/vol2/selma.html > [24/05/2013].

Hermoso, Borja, "El tiempo cabe en una caja", en El País Semanal. El País, 24 de abril de 2013, <http://elpais.com/elpais/2013/04/24/eps/13668047 46_581640.html $>$ [24/05/2013].

Mukarovsky, Jan, "El arte como hecho semiológico", en Escritos de estética y semiótica del arte, Barcelona, Gustavo Gili, 1977.

Tillmans, Wolfgang, Entrevista en el Museo Banco de la República, Bogotá, Colombia, <http://www.youtube.com/watch?v=QQ339pdaVfQl> [10/12/2012]. 